\title{
INOKULASI GANDA Glomus sp. DAN Pisolithus arrhizus MENINGKATKAN PERTUMBUHAN BIBIT Eucalyptus pellita F. Muell (Double Inoculation of Glomus sp. and Pisolithus arrhizus Improved Eucalyptus pellita F. Muell Seedling Growth)*
}

\author{
Oleh/By: \\ Ragil S. B. Irianto \\ Pusat Litbang Hutan dan Konservasi Alam \\ Jl. Gunung Batu No. 5 Po Box 165; Telp. 0251-8633234, 7520067; Fax 0251-8638111 Bogor \\ E-mail : Ragilirianto@yahoo.com \\ *Diterima : 13 April 2009; Disetujui : 30 September 2009
}

\begin{abstract}
Eucalyptus pellita F. Muell can perform symbiosis with two kinds of mycorrhizas, i.e. arbuscular mycorrhizal fungi (AMF) and ectomycorrhizal fungi (EF). This plant has already been planted by some industrial forest plantations in marginal lands in Sumatra and Kalimantan Island for pulp and paper. In such situation, AMF and EF may play a significant role in improving seedling growth in nursery and further assist plants to grow well in harsh condition. The aim of this research is to know the effect of AMF and EF inoculation to 3-monthold seedling of E. pellita. This research was conducted in the nursery with three inoculation treatments: noninoculated control, single inoculation of Glomus sp., and double inoculation of Glomus sp. and Pisolithus arrhizus. The result showed that single inoculation could increase height, diameter, dry weight, and $N$ and $P$ nutrient uptake by $13 \%, 13 \%, 40 \%, 32 \%$, and $82 \%$, respectively, compared to non-inoculated control seedlings. Double inoculation of Glomus sp. and P. arrhizus could increase significantly much higher growth than that of single-inoculated seedlings as measured in height, diameter, dry weight growth, $N$ and $P$ nutrient uptake by $41 \%, 41 \%, 80 \%, 64 \%$, and $155 \%$, respectively, compared to non-inoculated control seedlings. The results further suggested that double inoculation of AMF and EMF gave better seedling growth.
\end{abstract}

Keywords: Symbiosis, arbuscular mycorizal fungi, ectomycorrhizal fungi, forest, marginal land, improved growth

\begin{abstract}
ABSTRAK
Tanaman Eucalyptus pellita F. Muell dapat berasosiasi dengan dua jenis mikoriza, yaitu fungi mikoriza arbuskula dan fungi ektomikoriza. Tanaman ini mulai ditanam untuk bahan baku pulp dan kertas oleh beberapa perusahaan hutan tanaman industri terutama di lahan-lahan marjinal di Pulau Sumatera dan Kalimantan. Dalam situasi yang marjinal tersebut, fungi mikoriza arbuskula dan fungi ektomikoriza mempunyai peranan yang sangat nyata dalam meningkatkan pertumbuahn bibit di nurseri dan lebih lanjut akan membantu bibit tumbuh pada lahan yang marjinal. Penelitian ini bertujuan untuk memperoleh informasi tentang besarnya pengaruh inokulasi fungi mikoriza arbuskula dan fungi ektomikoriza terhadap pertumbuhan bibit E. pellita umur tiga bulan di pesemaian. Penelitian ini dilakukan di pesemaian dengan tanaman uji $E$. pellita yang diinokulasi dengan inokulan tunggal fungi mikoriza arbuskula jenis Glomus sp. dan inokulan ganda Glomus sp. yang dicampur dengan fungi ektomikoriza jenis Pisolithus arrhizus. Hasil penelitian menunjukkan bahwa inokulasi tunggal dapat meningkatkan pertumbuhan tinggi, diameter, berat kering, serapan unsur $\mathrm{N}$ dan $\mathrm{P}$ berturut-turut sebesar 13\%, 13\%, 40\%, 32\%, dan 82\% dibandingkan dengan kontrol. Sedangkan perlakuan inokulasi ganda antara Glomus sp. dan P. arrhizus dapat meningkatkan pertumbuhan tinggi, diameter, berat kering, serapan unsur N dan P berturut-turut sebesar 41\%, 41\%, 80\%, 64\%, dan 155\% dibandingkan dengan kontrol.
\end{abstract}

Kata kunci: Lahan marjinal, fungi mikoriza arbuskula, fungi ektomikoriza, Eucalyptus pellita F. Muell, pesemaian, Glomus sp., Pisolithus arrhizus 


\section{PENDAHULUAN}

Eucalyptus pellita F. Muell tumbuh secara alami di Australia, yaitu Queensland bagian utara $\left(12^{\circ}-18^{\circ} \mathrm{LS}\right)$ dan bagian selatan $\left(27^{\circ}-36^{\circ} \mathrm{LS}\right)$, Papua New Guinea (8 $-10^{\circ}$ LS) (Hall dan Brooker, 1974). Di Indonesia tanaman jenis ini tumbuh secara alami di daerah Merauke, yaitu antara Bupul dan Muting (Vercoe dan McDonald, 1990). Jenis tanaman ini tumbuh di daerah iklim basah pada kisaran elevasi yang cukup luas, yaitu antara 0-750 m dpl. dengan curah hujan rata-rata per tahun 900-2.300 mm dan suhu udara antara $6-16^{\circ} \mathrm{C}$ (NAS, 1983).

Pengembangan tanaman E. pellita di luar daerah sebaran alaminya telah dilakukan oleh beberapa negara, antara lain Brazil, Congo, Fiji, India, Indonesia, Kenya, Afrika Selatan, Uruguay (Anonim, 2008) dan Malaysia (Leksono dan Mashudi, 2003). Perusahaan Hutan Tanaman Industri (HTI) di Indonesia yang telah memulai menanam jenis tanaman ini secara luas, yaitu PT Arara Abadi. Disamping PT Arara Abadi, perusahaan lain yang juga mengembangkan jenis tersebut dalam skala terbatas, yaitu PT Inhutani III di Kalimantan Selatan, PT Perawang Sukses Perkasa Industri (PSPI) dan PT Riau Andalan Pulp and Paper (RAPP) di Riau, PT Surya Hutani Lestari dan PT Korindo Hutani di Kalimantan Timur (Leksono dan Mashudi, 2003).

Pengembangan jenis tanaman ini secara luas di Indonesia terutama dilakukan di Pulau Sumatera dan Kalimantan. Kedua pulau tersebut mempunyai jenis tanah dengan tingkat kesuburan yang rendah, oleh karena itu memerlukan masukan energi yang cukup besar untuk mendapatkan pertumbuhan yang optimal. Masukan energi yang biasa diberikan oleh perusahaan HTI di luar Jawa, yaitu pemberian pupuk kimia dan kompos. Pemberian pupuk yang minimal adalah pupuk yang mengandung unsur $\mathrm{N}$, $\mathrm{P}$, dan $\mathrm{K}$. Unsur $\mathrm{P}$ dalam tanah terutama di Pulau Kalimantan dan Sumatera pada umumnya cukup namun dalam keadaan tak tersedia bagi tanaman. Hal ini terjadi karena tanah di daerah tersebut mempunyai tingkat kemasaman yang tinggi, sehingga unsur $\mathrm{P}$ terikat oleh ion $\mathrm{Al}$ atau Fe. Untuk mengatasi masalah unsur $\mathrm{P}$ yang cukup namun tak tersedia bagi tanaman tersebut, fungi mikoriza arbuskula (FMA) dan fungi ektomikoriza (FE) dapat memainkan perannya dalam meningkatkan ketersediaan $\mathrm{P}$ bagi tanaman. Mikoriza mempunyai enzim fosfatase yang dapat melepaskan ion $P$ yang terikat.

Penelitian ini bertujuan untuk memperoleh informasi tentang besarnya pengaruh inokulasi fungi mikoriza arbuskula dan fungi ektomikoriza terhadap pertumbuhan bibit $E$. pellita umur tiga bulan di pesemaian.

\section{BAHAN DAN METODE}

\section{A. Tempat, Waktu, Bahan, dan Alat Penelitian}

Pembibitan E. pellita dilaksanakan di Desa Dawan Klod (posisi koordinat S 08 32.854', E 11526.304'), Kecamatan Dawan, Kabupaten Klungkung (Provinsi Bali) pada bulan September-Desember 2007, sedangkan kegiatan laboratorium dilaksanakan di Laboratorium Mikrobiologi Hutan, Pusat Penelitian dan Pengembangan Hutan dan Konservasi Alam, Bogor.

Bahan-bahan yang digunakan dalam pelaksanaan penelitian ini adalah: inokulan FMA jenis Glomus sp. dan FE jenis Pisolithus arrhizus, bahan pewarna staining dan destaining untuk akar tanaman, kantong plastik hitam (polybag, ukuran $10 \mathrm{~cm} \times 12 \mathrm{~cm}$ ), kantong plastik transparan (ukuran $100 \mathrm{~cm} \mathrm{x} 140 \mathrm{~cm}$ ), bak perkecambahan (ukuran $45 \mathrm{~cm}$ x $30 \mathrm{~cm}$ x 20 $\mathrm{cm}$ ), bahan pensteril tanah dengan bahan aktif Dazomet 3G, tanah subsoil pada kedalaman 20-40 cm, dan paranet. 
Alat-alat yang digunakan dalam penelitian ini adalah: kaliper, penggaris, mikroskop, kamera, embrat, dan timbangan analitik.

\section{B. Metode Penelitian}

\section{Perkecambahan}

Biji ekaliptus disterilisasi permukaannya dengan natrium hipoklorit 3\% selama lima menit untuk mematikan patogen yang menempel pada permukaan biji. Biji yang telah disterilisasi tersebut dikecambahkan pada bak kecambah (ukuran 45 $\mathrm{cm} \times 30 \mathrm{~cm} \times 20 \mathrm{~cm}$ ) yang berisi media kecambah steril. Media tersebut merupakan campuran antara pasir : tanah $=1: 3$ $(\mathrm{v} / \mathrm{v})$.

Bak perkecambahan tersebut disimpan dalam pesemaian yang diberi atap paranet dengan intensitas cahaya $45 \%$, kelembaban media dijaga dengan cara penyiraman air dengan alat embrat/sprayer yang dilakukan pada pagi dan sore hari.

\section{Inokulasi}

Kecambah ekaliptus yang tumbuh pada bak kecambah dipindah ke dalam polybag yang telah diisi dengan media steril, berupa campuran tanah dengan sekam padi dengan perbandingan 19:1 (v/v) untuk mendapatkan media dengan aerasi yang sesuai. Inokulan FMA diletakkan pada lubang tanam dalam polybag sebanyak lima gram sedangkan tablet ektomikoriza dibenamkan pada jarak tiga $\mathrm{cm}$ dari bibit dan kedalaman satu cm di bawah permukaan tanah.

\section{Rancangan Penelitian}

Percobaan dilakukan dengan Rancangan Acak Lengkap (RAL) (Mattjik dan Sumertajaya, 2002) dengan mikoriza sebagai faktor tunggal dengan tiga taraf, yaitu kontrol, Glomus sp. dan P. arrhizus. Ulangan untuk variabel tinggi dan diameter sebanyak 50 dan ulangan untuk variabel biomasa sebanyak 10 .
Variabel pertumbuhan tanaman yang diamati yaitu tinggi, diameter, dan biomasa. Variabel lain yang diukur adalah kandungan unsur $\mathrm{N}$, $\mathrm{P}$, dan $\mathrm{K}$ pada jaringan pucuk (daun dan batang).

Data dianalisis dengan bantuan program statistika JMP Start Statistics (Sall et al., 2005), data yang menunjukkan perbedaan yang nyata diuji lebih lanjut dengan uji Tukey.

\section{HASIL DAN PEMBAHASAN}

\section{A. Hasil Pengamatan}

Variabel yang diamati untuk mengetahui respon perlakuan terhadap partumbuhan bibit adalah tinggi, diameter, dan berat kering bibit pada umur tiga bulan setelah inokulasi di pesemaian.

\section{Tinggi Bibit}

Hasil analisis sidik ragam (anova) terhadap variabel pertumbuhan tinggi bibit E. pellita umur tiga bulan di persemaian menunjukkan perbedaan yang sangat nyata pada taraf $\mathrm{p}<0,0001$. Pada uji lanjut dengan uji Tukey menunjukkan bahwa perlakuan inokulasi secara tunggal dengan Glomus sp. maupun ganda antara Glomus sp. dan P. arrhizus berbeda nyata dibandingkan dengan kontrol (Tabel 1).

Inokulasi mikoriza, baik yang diberikan secara tunggal Glomus sp. maupun ganda perpaduan antara Glomus sp. dan $P$. arrhizus dapat meningkatkan pertumbuhan tinggi secara nyata berturut-turut sebesar $13 \%$ dan $41 \%$ dibandingkan dengan kontrol. Perlakuan inokulasi ganda antara Glomus sp. dan P. arrhizus dapat meningkatkan pertumbuhan tinggi jauh lebih baik tetapi secara statistik tidak berbeda nyata dibandingkan dengan inokulasi tunggal (Tabel 1 dan Gambar 1).

\section{Diameter Bibit}

Hasil analisis sidik ragam (anova) terhadap variabel pertumbuhan diameter bibit E. pellita umur tiga bulan di pesemaian menunjukkan perbedaan yang tidak 
Tabel (Table) 1. Pengaruh inokulasi tunggal Glomus sp. dan ganda Glomus sp. + P. arrhizus terhadap pertumbuhan tinggi, diameter, dan berat kering bibit E. pellita umur tiga bulan di pesemaian (Effect of single inoculation of Glomus sp. and double inoculation of Glomus sp. + $\mathrm{P}$. arrhizus on height, diameter, and dry weight of three-month-old E. pellita seedlings)

\begin{tabular}{lccc}
\hline \multicolumn{1}{c}{$\begin{array}{c}\text { Perlakuan } \\
\text { (Treatment) }\end{array}$} & $\begin{array}{c}\text { Tinggi (Height) } \\
(\mathrm{cm})\end{array}$ & $\begin{array}{c}\text { Diameter (Diameter) } \\
(\mathrm{mm})\end{array}$ & $\begin{array}{c}\text { Berat kering (Dry weight) } \\
(\mathrm{g})\end{array}$ \\
\hline Tanpa inokulasi (kontrol) & $46,20 \mathrm{a}$ & $2,12 \mathrm{a}$ & $1,9184 \mathrm{a}$ \\
(Non-inoculated/control seedling) & $(0)$ & $(0)$ & $(0)$ \\
Glomus sp. & $54,30 \mathrm{~b}$ & $2,40 \mathrm{a}$ & $2,6915 \mathrm{~b}$ \\
& $(13)$ & $(13)$ & $(40$ \\
Glomus sp. + P. arrhizus & $55,65 \mathrm{~b}$ & $2, .99 \mathrm{a}$ & $3,4490 \mathrm{c}$ \\
& $(41)$ & $(41)$ & $(80)$ \\
\hline
\end{tabular}

Keterangan (Remark):

1. Angka yang diikuti oleh huruf yang sama menunjukkan tidak ada perbedaan yang nyata pada taraf $\mathrm{p}=0,05$ berdasarkan uji Tukey (Numerics followed by the same letters are not significantly different at $p<0.05$ according to Tukey test)

2. Angka dalam tanda kurung adalah persentase peningkatan suatu variabel dibandingkan dengan kontrol yang didapat dari persamaan: [(perlakuan-kontrol)/kontrol) x 100\%] (Numerics in the parentheses denote percentage (\%) of a variable increase compared to control obtained from equation: [(treatment-control)/control x 100\%]

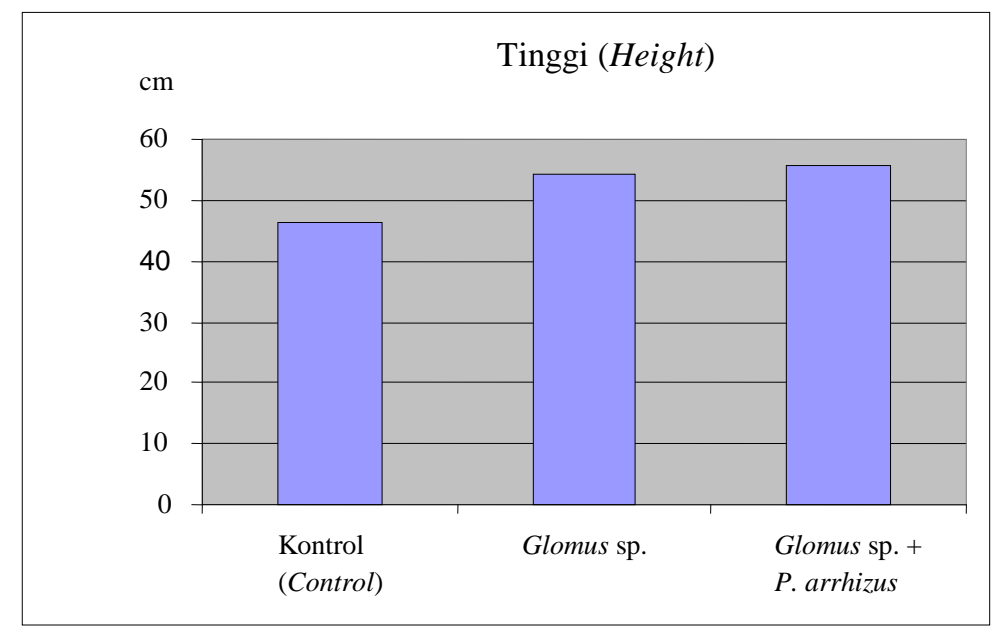

Gambar (Figure) 1. Pertumbuhan tinggi bibit E pellita umur tiga bulan di pesemaian yang mendapat perlakuan inokulasi tunggal Glomus sp. dan ganda Glomus sp. + P. arrhizus (Height growth of three-month-old E. pellita seedling in nursery inoculated with single inoculation Glomus sp. and double inoculation Glomus sp + P. arrhizus)

nyata (Tabel 1). Walaupun secara statistik tidak menunjukkan perbedaan yang nyata, peningkatan pertumbuhan diameter pada bibit yang diinokulasi tunggal maupun ganda memberikan peningkatan berturutturut sebesar 13\% dan 41\% dibandingkan dengan kontrol (Gambar 2).

\section{Berat Kering Bibit}

Hasil analisis sidik ragam (anova) terhadap variabel pertumbuhan berat kering bibit E. pellita umur tiga bulan di pesemaian menunjukkan perbedaan yang sa162 ngat nyata pada taraf $\mathrm{p}<0,0001$. Pada uji lanjut dengan uji Tukey menunjukkan bahwa perlakuan inokulasi tunggal dengan Glomus sp. dan ganda antara Glomus sp. dan $P$. arrhizus menunjukkan perbedaaan yang nyata dibandingkan dengan kontrol dan masing-masing perlakuan dapat meningkatkan pertumbuhan berat kering berturut-turut sebesar $40 \%$ dan 80\% dibandingkan dengan kontrol (Tabel 1). Perlakuan inokulasi ganda memberikan hasil yang berbeda nyata apabila dibandingkan dengan inokulasi tunggal dan 
kontrol. Inokulasi ganda dapat meningkatkan berat kering bibit umur tiga bulan di pesemaian sebesar $80 \%$ dibandingkan dengan kontrol dan setara dua kali lipat dibandingkan dengan inokulasi tunggal (Tabel 1 dan Gambar 3).

\section{Analisis Jaringan}

Perlakuan inokulasi tunggal dengan Glomus sp. dan inokulasi ganda antara
Glomus sp. dan P. arrhizus dapat meningkatkan kandungan unsur $\mathrm{N}$ pada jaringan batang dan daun (pucuk) berturut-turut sebesar 32\% dan 64\%, unsur P berturutturut sebesar $82 \%$ dan 155\% dibandingkan dengan kontrol (Tabel 2). Perlakuan inokulasi ganda memberikan pengaruh yang lebih baik dan berbeda nyata apabila dibandingkan dengan perlakuan inokulasi tunggal dan kontrol.

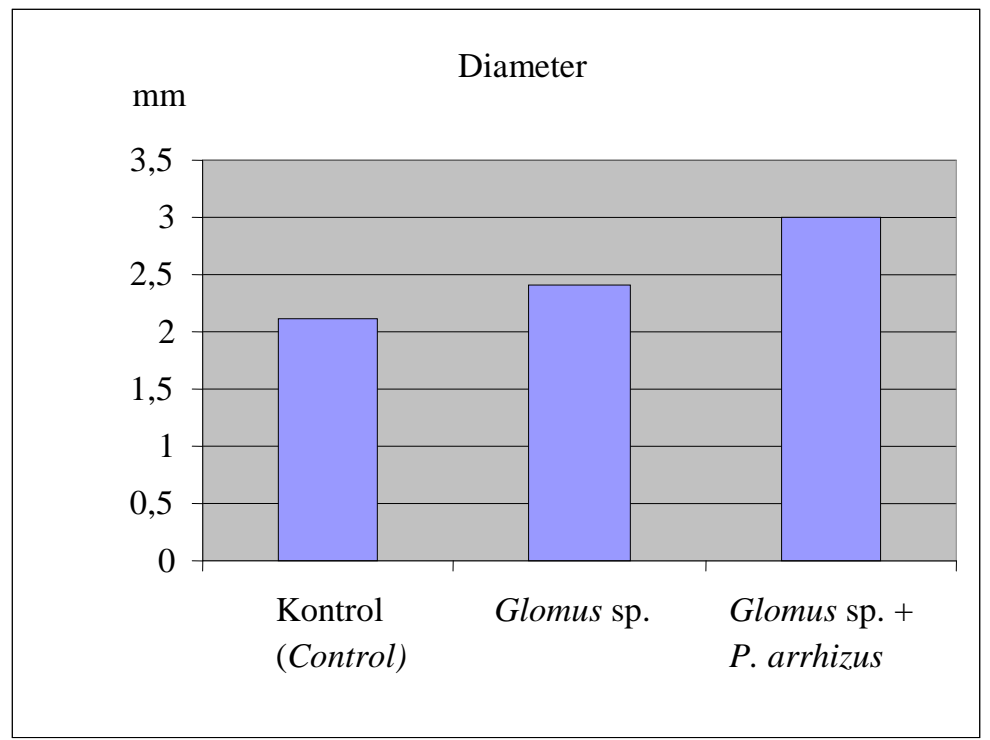

Gambar (Figure) 2. Pertumbuhan diameter bibit E pellita umur tiga bulan di pesemaian yang mendapat per-lakuan inokulasi tungal Glomus sp. dan ganda Glomus sp. + P. arrhizus (Diameter growth of three-monthold E. pellita seedling in nursery inoculated with single inoculation Glomus sp. and double inoculation Glomus $s p+$ P. arrhizus)

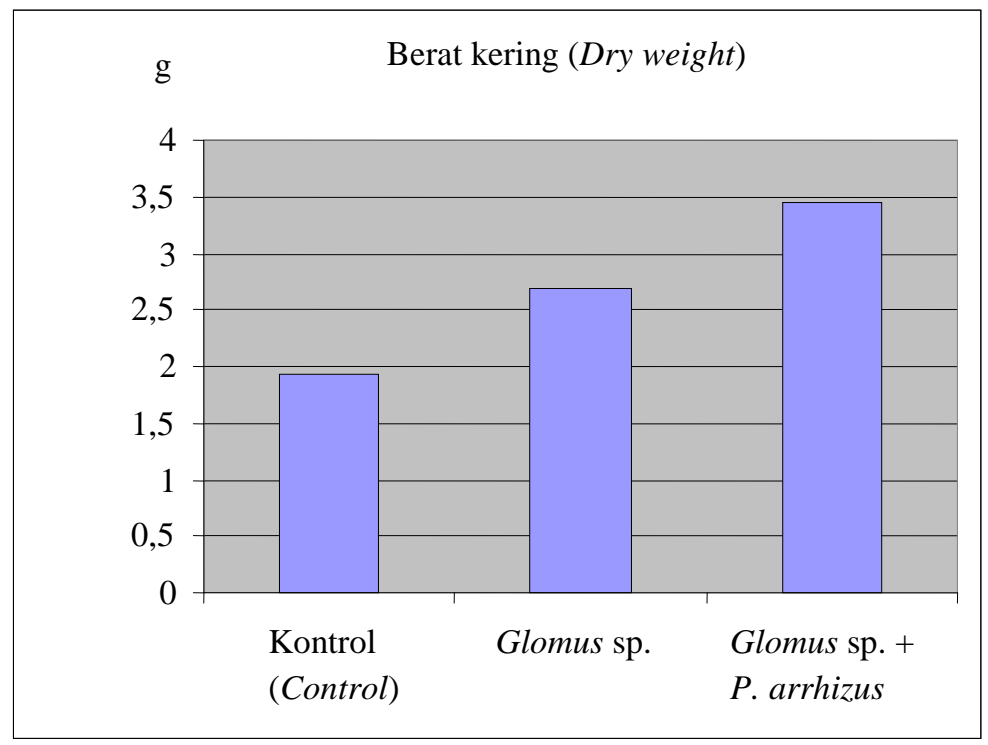

Gambar (Figure) 3. Berat kering bibit E pellita umur tiga bulan di pesemaian yang mendapat perlakuan inokulasi tungal Glomus sp. dan ganda Glomus sp. + P. arrhizus arrhizus (Dry weight of three-month-old E. pellita seedling in nursery inoculated with single inoculation Glomus sp. and double inoculation Glomus $s p+$ P. arrhizus) 
Tabel (Table) 2. Pengaruh inokulasi tunggal Glomus sp. dan ganda Glomus sp. + P. arrhizus terhadap kandungan unsur $\mathrm{N}$ dan $\mathrm{P}$ pada batang dan daun (pucuk) bibit E. pellita umur tiga bulan (Effect of single inoculation of Glomus $s p$. and double inoculation of Glomus $s p .+\mathrm{P}$. arrhizus on $N$ and $P$ nutrient uptake of three-month-old E. pellita seedlings)

\begin{tabular}{lcc}
\hline \multicolumn{1}{c}{$\begin{array}{c}\text { Perlakuan } \\
\text { (Treatment) }\end{array}$} & $\begin{array}{c}\mathrm{N} \\
(\mathrm{mg} / \text { Bibit) }(\mathrm{mg} / \text { Seedling })\end{array}$ & $\begin{array}{c}\mathrm{P} \\
(\mathrm{mg} / \text { Bibit })(\mathrm{mg} / \text { Seedling })\end{array}$ \\
\hline Tanpa inokulasi (kontrol) (Non inoculated control) & $1,45 \mathrm{a}$ & $0,23 \mathrm{a}$ \\
& $(0)$ & $(0)$ \\
Glomus sp. & $1,91 \mathrm{c}$ & $0,42 \mathrm{c}$ \\
& $(32)$ & $(82)$ \\
Glomus sp. + P. arrhizus & $2,38 \mathrm{~b}$ & $0,59 \mathrm{~b}$ \\
& $(64)$ & $(155)$ \\
\hline
\end{tabular}

Keterangan (Remark): N: Nitrogen (nitrogen), P: Fosfor (phosphorous)

\section{B. Pembahasan}

Pada umumnya suatu tanaman berasosiasi dengan salah satu dari fungi mikoriza arbuskula atau fungi ektomikoriza. Namun demikian tanaman Eucalyptus spp. dapat berasosiasi dengan kedua jenis mikoriza, yaitu FMA dan FE (Brundrett et al., 1997; Sadadou dan Hargas, 2000; Jones et al., 1998; Adjoud et al., 1996; Malajczuk et al., 1981). Disamping itu, tanaman Acacia spp., Melaleuca spp., dan Alocasuarina spp. juga merupakan tanaman yang dapat berasosiasi ganda, baik dengan FMA maupun FE (Brundett et al., 1997).

Bibit E. pellita pada tingkat pesemaian menunjukkan tingkat ketergantungan terhadap inokulasi tunggal dan ganda yang cukup tinggi, yaitu sebesar $40 \%$ dan 80\%. Nilai tingkat ketergantungan terhadap mikoriza (mycorrhizal dependency) yang tinggi tersebut merupakan salah satu indikator bahwa inokulasi mikoriza, baik inokulasi tunggal maupun ganda sangat berguna untuk menghasilkan bibit yang sehat (vigor) di pesemaian dan selanjutnya bibit tersebut akan memberikan persen tanaman hidup yang lebih baik serta tahan terhadap kekeringan pada tanaman muda di lapang, tahan hidup pada tanah yang kekurangan nutrisi, dan tahan penyakit (Wilson et al., 1991).

Hasil penelitian ini menunjukkan bahwa pengaruh inokulasi mikoriza terhadap 164 bibit E. pellita pada semua variabel yang diamati yaitu tinggi, diameter, berat kering serta serapan unsur hara makro (N dan P) meningkat dibandingkan dengan perlakuan tanpa inokulasi (kontrol) (Tabel 1 dan Tabel 2). Peningkatan pertumbuhan ini kemungkinan besar terjadi karena adanya peningkatan penyerapan unsur $\mathrm{P}$ yang cukup besar dan nyata, yaitu sebesar $82-155 \%$ dan N sebesar 32-64\% (Tabel 2). Unsur fosfor (P) merupakan salah satu unsur faktor pembatas pada pertumbuhan tanaman di daerah tropis dan sub tropis. Di daerah tropis unsur $\mathrm{P}$ dalam tanah pada umumnya membentuk suatu senyawa tak larut (terkhelat) dengan sejumlah kation bervalensi dua dan tiga, seperti Al dan Fe (Begum dan Islam, 2005).

Unsur P memegang peranan yang sangat penting terutama dalam proses penyimpanan dan transportasi energi, yaitu sebagai penyusun ADP (adenosin difosfat) dan ATP (adenosin trifosfat) yang sangat penting dalam mengatur seluruh metabolisme tanaman. Energi yang diperoleh dari proses fotosintesis dan metabolisme karbohidrat disimpan dalam bentuk senyawa fosfat, selanjutnya digunakan untuk pertumbuhan dan reproduksi. Unsur ini sangat penting dalam pembentukan biji dan pertumbuhan akar, sehingga salah satu tanda dari cukup tidaknya pasokan fosfat dapat dilihat dari pertumbuhan akar tanaman (Havlin et al., 1999). Apabila ta- 
naman kecukupan fosfat, maka akan memiliki akar yang luas, hal ini akan membantu tanaman menjangkau sumber unsur hara yang lebih jauh, sehingga tanaman akan mendapatkan unsur hara lebih banyak.

Penelitian ini menunjukkan bahwa bibit yang diinokulasi dengan inokulum ganda antara FMA (Glomus sp.) dan FE ( $P$. arrhizus) mempunyai serapan $\mathrm{P}$ lebih baik dan berat kering bibit yang lebih besar (Tabel 2). Hal ini karena seperti telah disebutkan di atas bahwa bibit dengan perlakuan tersebut mempunyai kandungan $\mathrm{P}$ yang lebih baik untuk melakukan transfer energi. Transfer energi juga berperan dalam proses penyerapan unsur hara lainnya. Terbukti bibit yang diberi perlakuan tersebut mempunyai kandungan $\mathrm{P}$ hampir 1,5 kali lipat dengan yang diinokulasi tunggal (Tabel 2). Dengan demikian, bibit tersebut mempunyai metabolisme yang lebih baik apabila dibandingkan dengan bibit yang diberi perlakuan lainnya.

Bibit yang diberi perlakuan inokulasi ganda memberikan respon yang lebih nyata apabila dibandingkan dengan perlakuan inokulasi tunggal (Tabel 1 dan Tabel 2). Pada asosiasi ganda yang bersifat sinergis akan meningkatkan pertumbuhan yang lebih besar dibandingkan dengan inokulasi tunggal. Menurut Jakobsen dan Rosendahl (1990), tanaman yang membentuk asosiasi mikoriza mempunyai kewajiban memberi imbalan sebesar 10$20 \%$ dari hasil fotosintesa untuk pembentukan, memelihara dan fungsi dari struktur mikoriza. Pada asosiasi yang sinergis ini akan meningkatkan jumlah unsur hara $\mathrm{N}$ dan $\mathrm{P}$ yang diserap oleh bibit (Tabel 2).

Penambahan sekam padi pada media tumbuh dapat mempercepat pertumbuhan tinggi dan diameter bibit, pertambahan bobot kering dan meningkatkan angka indeks mutu bibit, dan meningkatkan unsur hara pada media tumbuh (Durahim dan
Hendromono, 2001). Suhardjo et al. (1993) melaporkan bahwa penambahan bahan organik pada media tumbuh dapat menjaga kelembaban tanah, meningkatkan hara tanaman, dan memperbaiki struktur tanah. Disamping itu, sekam padi dapat meningkatkan kekompakan media tumbuh dalam polybag/polytube, sehingga media tumbuh tetap utuh (tidak pecah) pada saat pengangkutan bibit dan penanaman di lapang. Hal ini akan meningkatkan persen tanaman jadi di lapang dan mengurangi biaya penyulaman (Irianto et al., 2003; Hendromono dan Durahim, 2004; dan Valli, 1994).

\section{KESIMPULAN DAN SARAN}

\section{A. Kesimpulan}

Inokulasi ganda antara Glomus sp. dan $P$. arrhizus dapat meningkatkan secara nyata variabel tinggi, berat kering bibit, serapan unsur $\mathrm{N}$ dan $\mathrm{P}$ bibit $E$. pellita umur tiga bulan di pesemaian dibandingkan dengan kontrol, yaitu berturut-turut sebesar $41 \%$, 80\%, 64\%, dan 155\%.

\section{B. Saran}

Perlakuan inokulasi ganda antara Glomus sp. dan P. arrhizus dapat diaplikasikan pada pesemaian-pesemaian yang memproduksi bibit Eucalyptus dalam program rehabilitasi lahan dan hutan, baik yang dibiayai oleh pemerintah maupun swadaya masyarakat.

\section{DAFTAR PUSTAKA}

Adjoud, D., C. Plechette, R. H. Hargas and F. Lapeyrie. 1996. Response of 11 Eucalyptus Species to Inoculation with Three Arbuscular Mycorrhizal Fungi. Mycorrhizae 6 (2): 129-135.

Anonim. 2008. Agro Forestry Tree Database, A Tree Species Reference and Selection Guide. 
Begum, H. H. and M. T. Islam. 2005. Role of Synthesis and Exudation of Organic Acids in Phosphorus Nutrition in Plants in Tropical Soils. Biotechnology 4 (4): 333-340.

Brundrett, M; N. L. Bougher; B. Dell; T. Grove; N. Malajczuk. 1997. Working with Mycorrhizas in Forestry and Agriculture. Australian Centre for International Agricultural Research (ACIAR). Canberra, 374 p.

Durahim dan Hendromono. 2001. Kemungkinan Penggunaan Limbah Organik Sabut Kelapa Sawit dan Sekam Padi sebagai Campuran Top Soil untuk Media Pertumbuhan Bibit Mahoni (Swietenia macrophylla King). Bul. Pen. Hutan 628: 13-26. Pusat Penelitian dan Pengembangan Hutan dan Konservasi Alam. Bogor.

Hall, N. and Brooker. 1974. LargeFruited Red Mahagony-Eucalyptus pellita F. Muell. Forest Tree Series No. 146. Canbera, Australia.

Havlin, J. L., J. D. Beaton, S. L. Tisdale, dan W. L. Nelson. 1999. Soil Fertility and Fertilizer: An Introduction to Nutrient Management. Prentice Hall. New Jersey.

Hendromono dan Durahim.2004. Pemanfaatan Limbah Sabut Kelapa Sawit dan Sekam Padi Sebagai Medium Pertumbuhan Bibit Mahoni Afrika (Khaya anthoteca C. Dc). Bul. Pen. Hutan 644: 51-62. Pusat Penelitian dan Pengembangan Hutan dan Konservasi Alam. Bogor.

Irianto, R.S.B., E. Santoso, M. Turjaman, E. Widyati, dan I. R. Sitepu. 2003. Teknik Aplikasi Cendawan Mikoriza Arbuskular (CMA) dan Mikroba Sinergisme untuk Minimasi Top Soil pada Pesemaian Jati (Tectona grandis Linn.) di Perum Perhutani. Laporan Akhir Kerjasama Penelitan antara Puslitbang Hutan dan Konservasi Alam dan Perum Perhutani. $25 \mathrm{p}$.
Jakobsen, I. and L. Rosendahl. 1990. Carbon Flow Into Soil and External Hyphae from Root of Mycorrhizal Cucumber Plants. New Phytol. 115: 77-83.

Jones, M. D., D. M. Durall, and P. B. Tinker. 1998. A Comparison of Arbuscular and Ectomycorrhizal Eucalyptus coccifera Hook f.: Growth Response, Phosphorus Uptake Efficiency and External Hyphal Production. New Phytol. 140: 125-134.

Leksono, B. dan Mashudi. 2003. Teknik Pesemaian dan Informasi Benih Eucalyptus pellita F. Muell. Pusat Penelitian dan Pengembangan Bioteknologi dan Pemuliaan Tanaman Hutan.

Malajczuk, N., R. G. Linderman, J. Kough, and J. M. Trappe. 1981. Presence Vesicular Arbuscular Mycorrhizae in Eucalyptus spp. and Acacia sp. and Their Absence in Banksia sp. after Inoculaton with Glomus fasciculatus. New Phytol. 87: 567-572.

Mattjik, A. A. dan I. M. Sumertajaya. 2002. Perancangan Percobaan dengan Aplikasi SAS dan Minitab. IPB Press. 282 p.

NAS (National Academy of Science). 1983. Fuel Wood Crops-Shrub and Tree Species for Energy Production. National Academy Press Vol. 2. Washington DC.

Sadadou, D. and R. H. Hargas. 2000. Occurrence of Arbuscular Mycorrhizae on Aged Eucalyptus. Mycorrhizae 9 (5): 287-290.

Sall, J., L. Creighton, and A. Lehman. 2005. JMP Start Statistics $3^{\text {nd }}$, A Guide to Statistics and Data Analysis Using JMP and JMP IN Software. $560 \mathrm{p}$.

Suhardjo, M. Soepartini, dan U. Kurnia. 1993. Bahan Organik Tanah. Informasi Penelitian Tanah, Air, Pupuk, dan Lahan. 
Valli, I. 1994. Essential Elements of Reforestation: a Prope Nursery. In "Seminar from Grassland to Forest: Probable and Sustainable Reforestation of Alang-Alang in Indonesia”. Jakarta 11-12 Januari 1994.

Vercoe, T. K. and M. W. McDonald. 1990. Eucalyptus pellita F. Muell and Acacia Seed Collections in New Guinea, September-October 1990.
Australian Tree Seed Centre. CSIRO Division of Forestry.

Wilson J., R. C. Munro, K. Ingleby, P. A. Mason, M. P. N. Jefwa, J. M. C. P. Dick, and R. R. B. Leaky. 1991. Tree Establishment in Semi Arid Land of Kenya - Role of Mycorrhizal Inoculation and Water Retaining Polymer. For. Ecol. Manage. 45: 153-163. 